\title{
EFFECT OF LAMINATE VENEER DESIGNS ON ABFRACTION INCIDENCE USING DIFFERENT LOADING CONDITIONS "FINITE ELEMENT ANALYSIS"
}

\author{
Adel A. El Badawy*, Mohammed H. Abd El Aziz* and Elsayed A. Omar*
}

\begin{abstract}
Statement of problem: Abfraction incidence is usually challenging and difficult to be identified accurately, especially, in case of existing restoration.
\end{abstract}

Aim of the study: This study aimed to evaluate the influence of laminate veneer design on abfraction incidence in maxillary central incisor with different loading protocols using finite element analysis.

Materials and methods: Maxillary central incisor was subjected to Computerized tomography (CT) scan to obtain 3D finite element model. Tooth without restoration (control) was subjected to a load of $100 \mathrm{~N}$ at $60^{\circ}$ and $125^{\circ}$, the same load was applied with the previous directions on the tooth model with lithium disilicate laminate veneer using three preparation designs: veneer is taken up to the incisal edge level but the edge, is not reduced (Feather) (FP), design (FP) is prepared with $0.5 \mathrm{~mm}$ incisal reduction without palatal overlapping (Butt joint.) (BJP) and (POP) in which, design (FP) is prepared with $2 \mathrm{~mm}$ incisal reduction and $0.5 \mathrm{~mm}$ palatal overlap.

Results: In feather preparation (FP) design, stress values were slightly higher than that in control model in enamel and dentin at both load directions. While, but joint preparation (BJP) design exhibited the lowest stress in both layers and direction of load.

Conclusion Highest stresses were concentrated at the cement - enamel junction in all loading scenarios, butt joint preparation (BJP) design in both load conditions developed lower stresses than that in other designs, and feather preparation (FP) design suggested the probability of abfraction formation.

* Assistant professor, Crown and Bridge Department, Faculty of Dentistry, Al Azhar University 


\section{INTRODUCTION}

Laminate veneer restorations are a common treatment option to rehabilitate the aesthetic properties of discolored, damaged or worn teeth. ${ }^{[1]}$ The improvement in bonding systems, ceramic materials, and fabrication techniques, have changed the manner we deal with such type of restorations. ${ }^{[2]}$ Three tooth-preparation designs are available for laminate veneers. The window preparation is a nonoverlap design that maintains an intact incisal edge. By contrast, incisal edge is reduced in butt joint preparation and overlapped incisal palatal chamfer preparation. ${ }^{[3-7]}$

Based on their physical and mechanical properties, high strength lithium di silicate is indicated for esthetic anterior restorations. ${ }^{[8]}$ Lithium disilicate veneers reproduce translucency, polychromatism and are biologically compatible with periodontal tissue. ${ }^{[7,9]}$ Abfraction formed from excessive non - axial loading forces, which concentrates on the weak cervical region causing breakdown of bond among hydroxyapatite of the enamel layer near to cemento - enamel junction leading to micro fractures, chipped enamel and tooth structure loss. ${ }^{[10]}$ Finite element analysis is an essential numerical method that can be applied to study the influence of material properties and loading protocol on the stress pattern and distribution for different designs of restorations. ${ }^{[11]}$

This study aimed to evaluate the effect of laminate veneer design on abfraction incidence in maxillary central incisor under different loading protocols using finite element analysis

\section{MATERIALS AND METHODS}

Maxillary central incisor with $26 \mathrm{~mm}$ length (free of dental caries, restorations, incisal attrition or developmental anomalies) was selected and fixed at the base of a plastic mould $(2 \times 2 \times 3 \mathrm{~cm})$ using a slice of wax. Using dental surveyor, the tooth was aligned with its axis vertical to the horizontal plane of the mould. Molten wax was then poured within the plastic mould to cover the maxillary canine entirely. Computerized tomography (CT) scan (HiSpeed NX/I, General Eletric, Denver, CO, USA) with image quality $120 \mathrm{kV}, 150 \mathrm{~mA}, 512$ x 512 matrix and slice thickness of $0.25 \mathrm{~mm}$ to divide the tooth into 104 sections. Scanning was performed in a labio - palatal direction starting from the apex up to the incisal edge to obtain 105 image levels.

Each image level of the Computerized tomography scan was pointed randomly by 48 points (K points) (enamel or cementum 16, dentin 16 , and pulp 16). The length of the margins of the plastic mould were used as a fixed reference for " $\mathrm{X}$ " and " $\mathrm{Y}$ " axis. The " $\mathrm{X}$ " axis was pointed labio - palatally dividing the margin of the plastic mould into two equal right and left halves, also, the "Y" axis was pointed mesio-distally dividing the margin of the plastic mould into two equal upper and lower halves. From Computerized tomography scan, $5040 \mathrm{~K}$ points were obtained, each $\mathrm{K}$ point has a three distances, $\mathrm{x}, \mathrm{y}$, (distances from $\mathrm{X}$ and $\mathrm{Y}$ axis) and $\mathrm{z}$ (slice level $\mathrm{x}$ 0.25). The collected $\mathrm{x}, \mathrm{y}$, and $\mathrm{z}$ distances (three dimensions) for each $\mathrm{K}$ point was introduced into special program for stress analysis (ANSYS 15.0 finite element software) to obtain 3D finite element model divided into cubical volumes. Model refining and meshing have been done digitally forming model with (262588) elements and (404928) nodes. Then, the geometric configurations of the laminate veneer preparation designs and their dimensions simulating a clinical preparation protocol were introduced into the ANSYS software program, $(0.5 \mathrm{~mm}$ buccal and proximal reduction plus $0.1 \mathrm{~mm}$ for cement layer, cervical margin placed $1.0 \mathrm{~mm}$ away from the cemento - enamel junction) and $0.5 \mathrm{~mm}$ chamfer made for all finish lines. ${ }^{[1,12,13]}$. Figure (1) 


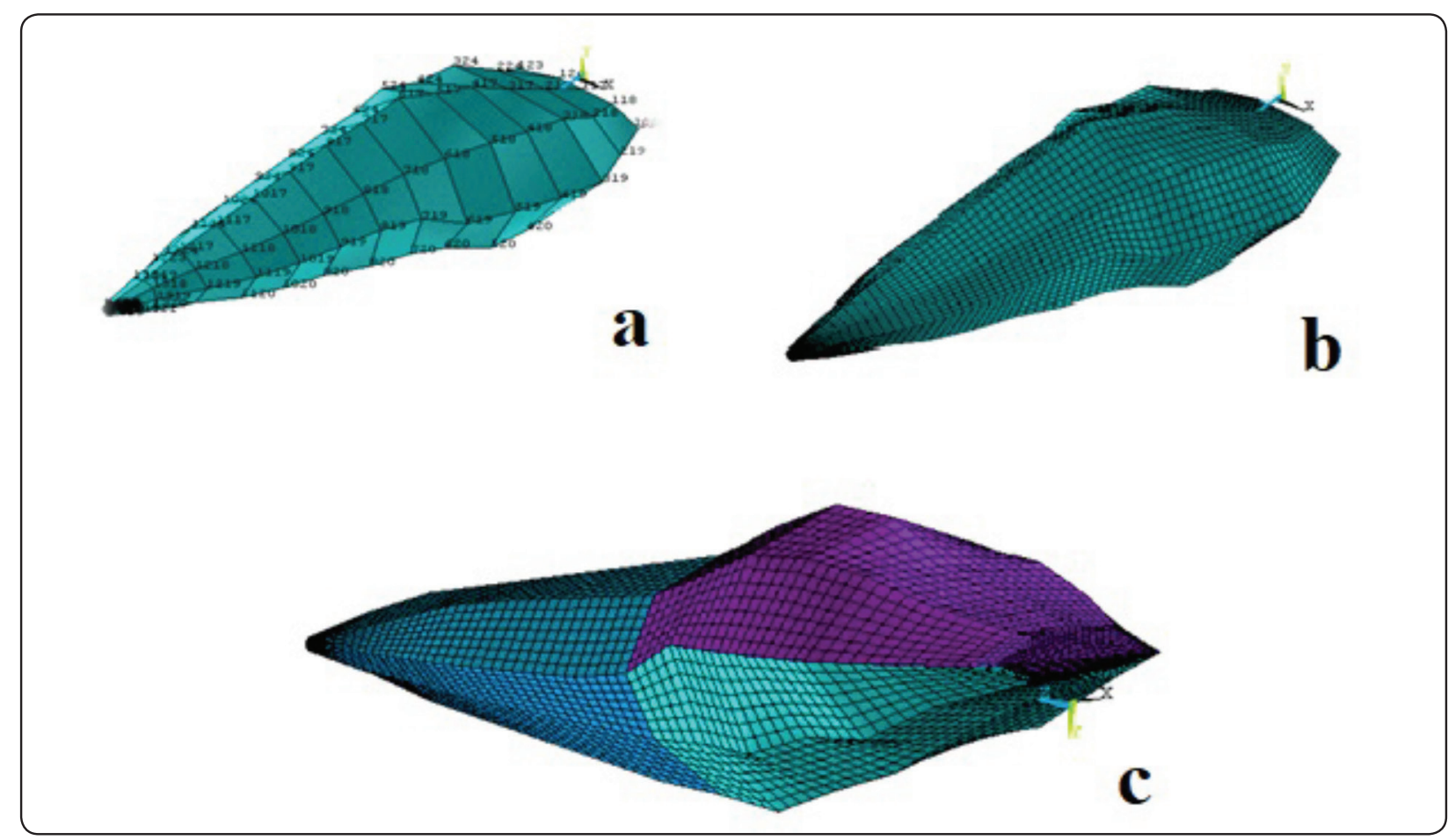

Fig. (1) Steps of finite element model preparation, a) model with cubic volumes, b) model mashing and c) configurations of the laminate veneer preparation designs and thier dimensions.

Tooth without restoration which used as a control was subjected to a load of $100 \mathrm{~N}$ at $60^{\circ}$ (tearing) and $125^{\circ}$ (protrusion) $)^{[12-14]}$ The same load was applied with the previous directions on the tooth model with lithium disilicate laminate veneer ${ }^{[12]}$ with the following preparation designs: veneer is taken up to the height of the incisal edge but the edge, is not reduced (Feather) (FP), design (FP) is prepared with $0.5 \mathrm{~mm}$ incisal reduction without palatal overlapping (Butt joint.) (BJP) and (POP) in which, design (FP) is prepared with $2 \mathrm{~mm}$ incisal reduction and $0.5 \mathrm{~mm}$ palatal overlap. ${ }^{[2,11]}$ Stress distribution and its strength on the model of tooth with the laminate veneer were given both in color strips and numerical stress values. ${ }^{[15]}$

Modulus of elasticity, and Poisson's ratio of used materials and tooth components Table (1) were introduced to the ANSYS software program which in turn calculated stresses pattern and distribution at the cervical region under three different loading scenarios (Compressive, Tensile and shear stress analyses) which were carried out to identify Von Mises stresses (the equivalent stress of principal stresses in $X, Y, Z$ directions $)=1 / 2[(\sigma 1-\sigma 2) 2+$ $(\boldsymbol{\sigma} 2-\boldsymbol{\sigma} 3) 2+(\boldsymbol{\sigma} 3-\boldsymbol{\sigma} 1) 2]$ where $\sigma 1, \sigma 2$, and $\sigma 3$ are principal stresses and $\sigma 1>\sigma 2>\sigma 3$

TABLE 1. Material properties used in the finite element models

\begin{tabular}{|c|c|c|c|}
\hline Materials & $\begin{array}{c}\text { Young's } \\
\text { Modulus Mpa }\end{array}$ & $\begin{array}{c}\text { Poisson's } \\
\text { Ratio }\end{array}$ & References \\
\hline Enamel & 84100 & 0.33 & {$[16]$} \\
\hline Dentin & 14700 & 0.31 & {$[16]$} \\
\hline Periodontal lig. & 69 & 0.45 & {$[17]$} \\
\hline Cancellous bone & 10700 & 0.3 & {$[16]$} \\
\hline Pulp & 2 & 0.45 & {$[15]$} \\
\hline Resin cement & 6000 & 0.3 & {$[18]$} \\
\hline IPS e-max & 67,000 & 0.22 & {$[19]$} \\
\hline
\end{tabular}




\section{RESULTS}

The four tested models (control and three different preparation designs) showed that, Von Mises stress value created in enamel was higher than in dentine when the finite element model was subjected to $100 \mathrm{~N}$ at $60^{\circ}$ and $125^{\circ}$ applied load, also, this value was higher at $125^{\circ}$ applied load than that at $60^{\circ}$ applied load (Table 2).

TABLE 2: Maximum VonMises stress values (Mpa) in the cervical enamel and dentin

\begin{tabular}{|c|c|c|c|c|c|}
\hline $\begin{array}{c}\text { Tooth } \\
\text { structure }\end{array}$ & $\begin{array}{c}\text { Applied } \\
\text { load }\end{array}$ & $\begin{array}{c}\text { Control } \\
\text { Model }\end{array}$ & $\begin{array}{c}\text { Design } \\
(\mathrm{FP})\end{array}$ & $\begin{array}{c}\text { Design } \\
\text { (BJP) }\end{array}$ & $\begin{array}{c}\text { Design } \\
\text { (POP) }\end{array}$ \\
\hline \multirow{2}{*}{ Enamel } & $60^{\circ}$ & 10.3 & 13.4 & 9.8 & 12.3 \\
\cline { 2 - 6 } & $125^{\circ}$ & 33.4 & 36.2 & 32.7 & 33.1 \\
\hline \multirow{2}{*}{ Dentin } & $60^{\circ}$ & 9.5 & 12.9 & 8.7 & 10.7 \\
\cline { 2 - 6 } & $125^{\circ}$ & 30.7 & 31.9 & 27.5 & 29.4 \\
\hline
\end{tabular}

FP: Feather preparation $\quad$ BJP: Butt joint preparation POP: Palatal overlap preparation

In case of $60^{\circ}$ applied load, maximum stress values at the enamel and dentin of labial cervical region for control model were (10.3 and 9.5 Mpa) respectively, while in case of $125^{\circ}$ applied load, maximum stress values were (33.4 and $30.7 \mathrm{Mpa})$ respectively, indicating to better stress distribution in dentin layer than in enamel at such region. Figure (2)

In feather preparation (FP) design, Von Mises equivalent stress values were slightly higher than that in control model in both enamel and dentin at both directions of directed load as shown in table (2). While Von Mises equivalent stress values in butt joint preparation (BJP) design were the best in both layers and direction of load which were slightly lower than that in Palatal overlap (POP) design. (Figure 3 and 4 )

In control model and design (A), the stress was concentrated at the incisal regions of the laminate veneer and then progressively decreased along the labial wall (different successive strips of colors) giving indication of good stress distribution, however in designs (B), and (C), the stress was concentrated and nearly localized at the incisal region of the laminate veneer (blue blot at the middle part of the incisal region and only green color over the remaining tooth surfaces). (Figure 5)

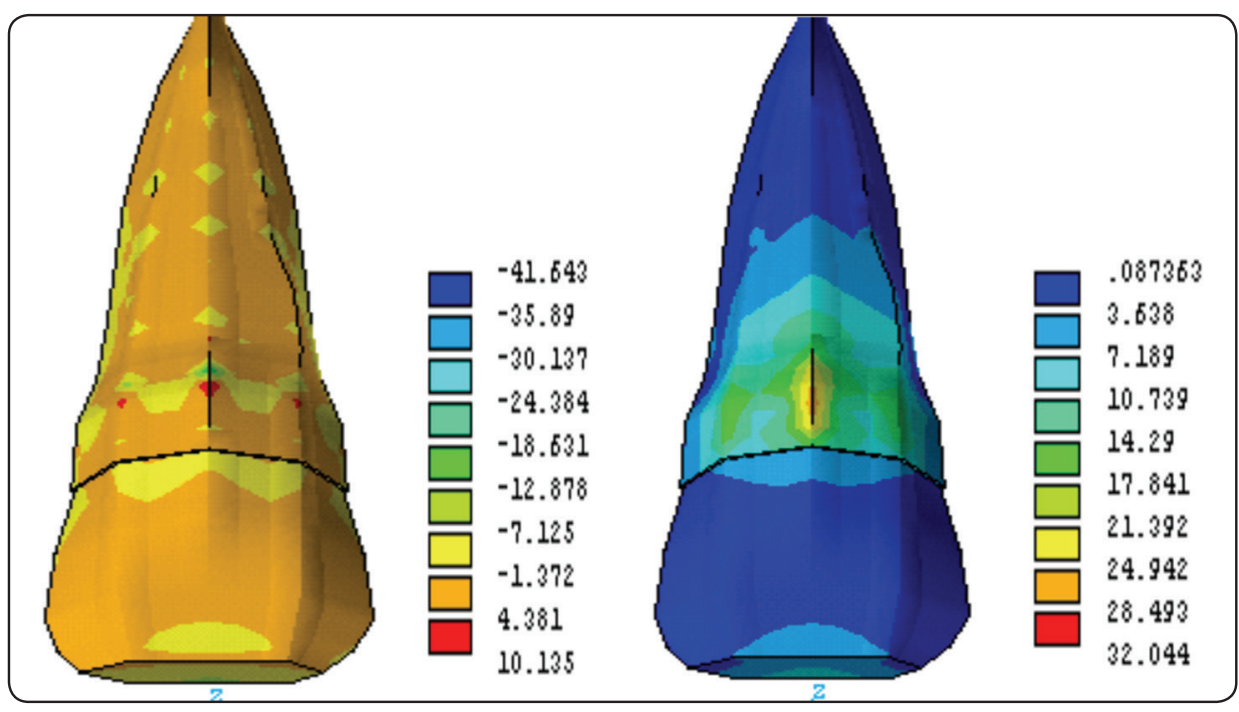

Fig. (2) Stress distribution in both enamel and dentin at labial cervical region. 


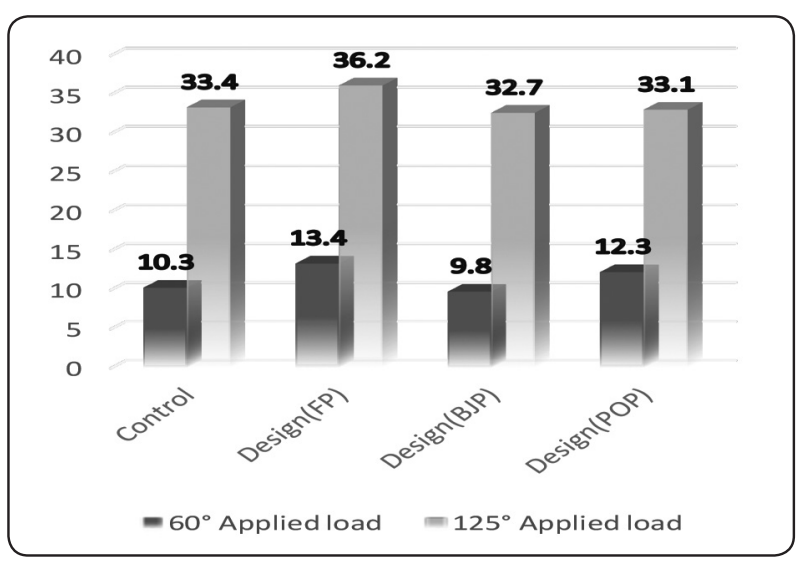

Fig. (3) Von Mises equivalent stress values in enamel (Mpa)

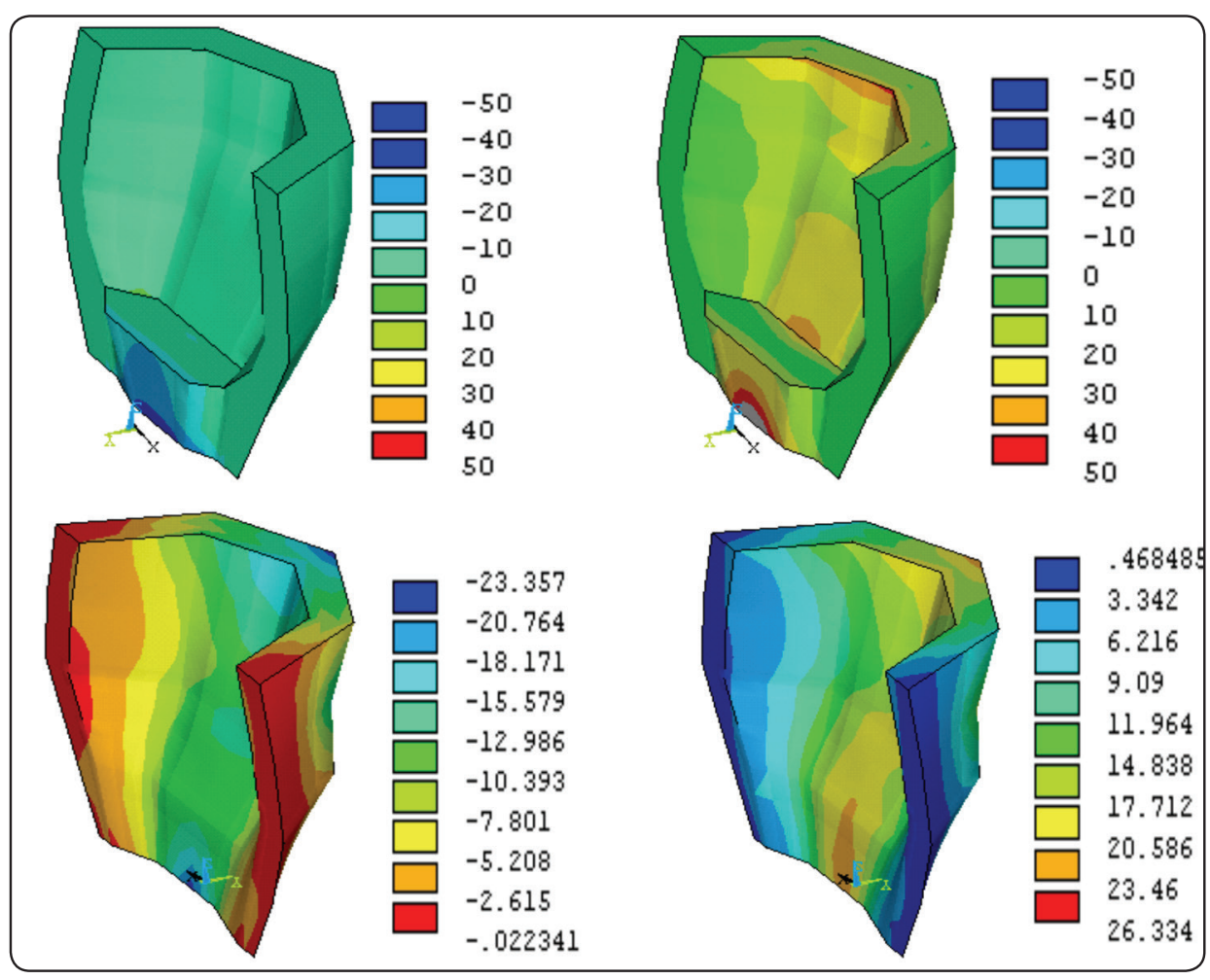

Fig. 5) Stress distribution in both enamel and dentin at labial cervical region.

\section{DISCUSSION}

Some variables in biomedical field cannot be assessed through in vivo models, as it would be ethically controversial to conduct them on live subjects. Therefore, virtual simulation approaches and models, such as finite element analysis become an essential means of evaluation in biomedical materials. The method includes a geometric process that can be utilized to consider the effect of material prop-

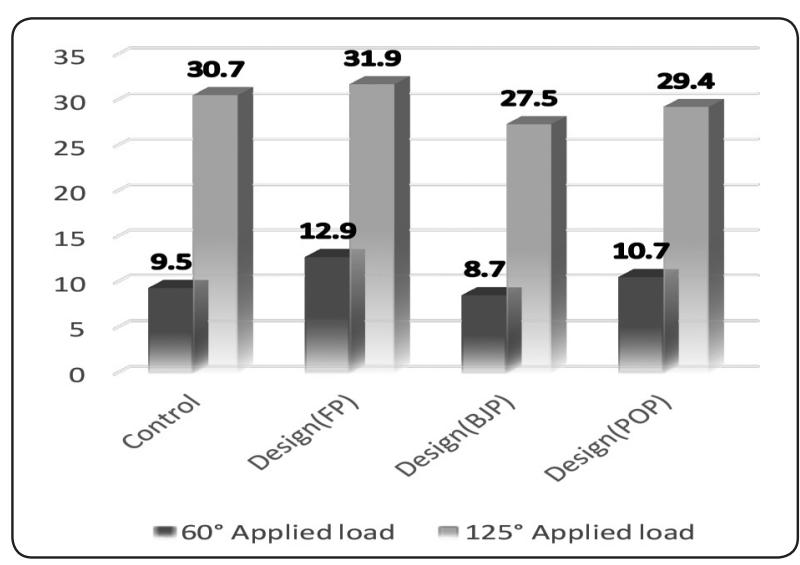

Fig. (4) Von Mises equivalent stress values in dentin(Mpa)

erties, loading, geometry, and process variables on the stress distribution in dental restorations. ${ }^{[11,13,20]}$ In our study, finite element model gained from a segmented micro-CT data which has been authorized by various studies. ${ }^{[21,22]}$ This model representing the tooth with three designs of lithium disilicate laminate veneer subjected to two different incisal loading scenarios to evaluate the actual stress on enamel and dentine within acceptable accuracy limits. ${ }^{[23]}$ 
In spite of, some research findings have cast some doubt on that, the direction of incisal load is a prime cause for hydroxyapatite breakdown at the cervical region of the buccal surface, the results of our study contributed to predicting the probability of abfraction incidence in the presence of definite types of laminate veneer designs with lithium disilicate material. ${ }^{[24,25]}$ Abfraction is obtained as a result of tensile forces mostly in the form of wedge-shape and located at region of maximum stress, where, in an ideal occlusion, functional loads are directed along the long axis of the tooth, but, in eccentric movements the side towards which the tooth is bending under compressive stress and the opposed side is in tension. From other point of view, cervical enamel has a weak mechanical bond to the underlying dentin due to a lack of the normal scalloped pattern of the enamel-dentin junction in this area, and enamel has high compressive strength but its capability to withstand tensile forces is poor permitting the tensile forces acting on a tooth to disrupt bonds between hydroxyapatite crystals. ${ }^{[26-29]}$

The results of this research showed that, the values of stress in the cervical region of the labial surface were higher in the enamel than in dentine, which indicates that, breaking of enamel might occur in these layers exactly. ${ }^{[30]}$ Also, the calculated Von Mises stress in the cervical part of the tooth under $60^{\circ}$ incisal load is not high and measured up to $13.4 \mathrm{MPa}$, whereas the stresses in the same part of the tooth under $125^{\circ}$ incisal load are significantly high and measured over $36 \mathrm{MPa}$, which are corresponded the results of other previous study. ${ }^{[31]}$

The results of this study exhibited that, stress values in the cervical tooth part in butt joint preparation design (BJP) under $60^{\circ}$ and $125^{\circ}$ were lower than other preparation designs which are in accordance with that of Castelnuovo et al ${ }^{[32]}$ and Prasanth et al. ${ }^{[33]}$. Who mentioned that, butt joint design preserves the peripheral enamel layer around all the margins, which helps in counteracting shear stresses better and distributing the incisal loads on a broader area than with other designs. From other hand, the palatal part of the laminate veneer in the incisal overlap preparation is subjected to a compressive force, so the incisal part of ceramic cannot homogeneously distribute the load from the veneer to the underlying layer of resin cement and finally to the dentin, so, the stress was mainly concentrated at the level of the veneer structure. Nevertheless, in butt joint preparation design under $125^{\circ}$ incisal load, a broader area of tooth structure is involved. ${ }^{[12]}$

In the present study, the direction of loading (both centric and eccentric movements) recorded a significant effect on the results, where, Von Mises stress values in the cervical tooth part at $125^{\circ}$ applied load were apparently higher than that at $60^{\circ}$ applied load. Some authors ${ }^{[33]}$ have loaded the veneers at $\left(0^{\circ}\right)$ to study the influence of vertical component of incising force on the survival rate. But this direction of incisal load was not analyzed in this study because, stresses that affect laminate veneers in maxillary incisors during function are not parallel to the long axis of the tooth. ${ }^{[32]}$.

For all the models, ceramic veneer absorbed most of exerted stress (because, ceramic has high modulus of elasticity than dental tissues and resin cement). In contrast, the cement layer behaved like a stress absorber. Butt joint preparation (BJP) design enabled the laminate veneer to have an incisal margin composed of ceramic, which resulted in a limitation in the transmission of stress to the cement layer. ${ }^{[14]}$ According to the outcomes of this study, an butt joint preparation (BJP) design could be a more favorable option for ceramic laminate veneers as it has a high clinical success rate, more uniform stress distribution in the cement layer, and lower maximum principle stress. ${ }^{[1]}$ 


\section{CONCLUSION}

Within the limitation of this study, the following conclusions might be drawn:

1. Maximum stresses generated by protrusion $\left(125^{\circ}\right)$ were generally higher than that by tearing $\left(60^{\circ}\right)$

2. Peak stresses were concentrated at the cement enamel junction in all loading scenarios.

3. Butt joint preparation (BJP) design in both load conditions developed better stress distribution than other designs.

4. Feather preparation (FP) design suggested high possibility of occurrence of abfraction.

\section{REFERENCES}

1. Tugcu, E., et al., Marginal Adaptation and Fracture Resistance of Lithium Disilicate Laminate Veneers on Teeth with Different Preparation Depths. Int J Periodontics Restorative Dent, 2018.38(Suppl): p. s87-s95.

2. Chai, S.Y., et al., Incisal preparation design for ceramic veneers: A critical review. J Am Dent Assoc, 2018. 149(1): p. 25-37.

3. da Costa, D.C., et al., A meta-analysis of the most indicated preparation design for porcelain laminate veneers. J Adhes Dent, 2013. 15(3): p. 215-220.

4. Öztürk, E. and Ş. Bolay, Survival of porcelain laminate veneers with different degrees of dentin exposure: 2-year clinical results. Journal of Adhesive Dentistry, 2014. 16(5).

5. Hong, N., et al., Effect of Preparation Designs on the Prognosis of Porcelain Laminate Veneers: A Systematic Review and Meta-Analysis. Operative dentistry, 2017. 42(6): p. E197-E213.

6. Alothman, Y. and M.S. Bamasoud, The Success of Dental Veneers According To Preparation Design and Material Type. Open Access Maced J Med Sci, 2018. 6(12): p. 2402-2408.

7. Kusaba, K., et al., Effect of preparation design on marginal and internal adaptation of translucent zirconia laminate veneers. European journal of oral sciences, 2018. 126(6): p. 507-511.

8. Gonzaga, C.C., et al., Enamel and Dentin Surface Finishing Influence on the Roughness and Microshear Bond Strength of a Lithium Silicate Glass-Ceramic for Laminate Veneers. Int Sch Res Notices, 2015. 2015: p. 243615.

9. Sahyon,H.B.S., et al., Effect of previous photoactivation of the adhesive system on the color stability and mechanical properties of resin components in ceramic laminate veneer luting. The Journal of prosthetic dentistry, 2018. 120(4): p. 631. e1-631. e6.

10. Zi Yun, L., et al., Prevalence of non-carious cervical lesions and associated risk indicators in middle-aged and elderly populations in Southern China. Chin J Dent Res, 2015. 18(1): p. 41-50.

11. Ustun, O. and A.N. Ozturk, The evaluation of stress patterns in porcelain laminate veneers with different restoration designs and loading angles induced by functional loads: A three-dimensional finite element analysis study. Niger $\mathbf{J}$ Clin Pract, 2018. 21(3): p. 337-342.

12. Arora, A., et al., Evaluation of fracture resistance of ceramic veneers with different preparation designs and loading conditions: An in vitro study. J Indian Prosthodont Soc, 2017. 17(4): p. 325-331.

13. Li, Z., et al., A three-dimensional finite element study on anterior laminate veneers with different incisal preparations. J Prosthet Dent, 2014. 112(2): p. 325-33.

14. Zarone, F., et al., Influence of tooth preparation design on the stress distribution in maxillary central incisors restored by means of alumina porcelain veneers: a 3D-finite element analysis. Dent Mater, 2005. 21(12): p. 1178-88.

15. Chander, N.G. and T.V. Padmanabhan, Finite element stress analysis of diastema closure with ceramic laminate veneers. J Prosthodont, 2009. 18(7): p. 577-81.

16. Sorrentino, R., et al., Nonlinear visco-elastic finite element analysis of different porcelain veneers configuration. $\mathrm{J}$ Biomed Mater Res B Appl Biomater, 2009. 91(2): p. 727-36.

17. Rocha, E.P., et al., Mechanical behavior of ceramic veneer in zirconia-based restorations: a 3- dimensional finite element analysis using microcomputed tomography data. J Prosthet Dent, 2011. 105(1): p. 14-20.

18. Chang, Y.H., et al., Mechanical interactions of cuspalcoverage designs and cement thickness in a cusp-replacing ceramic premolar restoration: a finite element study. Med Biol Eng Comput, 2009. 47(4): p. 367-74.

19. Albakry, M., M. Guazzato, and M.V. Swain, Biaxial flexural strength, elastic moduli, and x-ray diffraction characterization of three pressable all-ceramic materials. J Prosthet Dent, 2003. 89(4): p. 374-80. 
20. Belli, S., O. Eraslan, and G. Eskitascioglu, Effect of root filling on stress distribution in premolars with endodonticperiodontal lesion: a finite elemental analysis study. Journal of endodontics, 2016. 42(1): p. 150-155.

21. Magne, P. and T. Oganesyan, Premolar cuspal flexure as a function of restorative material and occlusal contact location. Quintessence International, 2009. 40(5).

22. Magne, P. and T. Oganesyan, CT Scan--Based Finite Element Analysis of Premolar Cuspal Deflection Following Operative Procedures. International Journal of Periodontics \& Restorative Dentistry, 2009. 29(4).

23. Tajima, K., et al., Three-dimensional finite element modeling from CT images of tooth and its validation. Dental materials journal, 2009. 28(2): p. 219-226.

24. Michael, J., et al., Abfraction: separating fact from fiction. Australian dental journal, 2009. 54(1): p. 2-8.

25. Romeed, S.A., R. Malik, and S.M. Dunne, Stress analysis of occlusal forces in canine teeth and their role in the development of non-carious cervical lesions: abfraction. Int J Dent, 2012. 2012: p. 234845.

26. Francisconi, L.F., et al., The effects of occlusal loading on the margins of cervical restorations. The Journal of the
American Dental Association, 2009. 140(10): p. 1275-1282.

27. Lynch, C.D., et al., Hunter-Schreger Band patterns in human tooth enamel. Journal of Anatomy, 2010. 217(2): p. 106-115.

28. Silva, A.G., et al., The association between occlusal factors and noncarious cervical lesions: a systematic review. Journal of dentistry, 2013.41(1): p. 9-16.

29. Sawlani, K., Clinical Evaluation of Non-carious Cervical Lesions: A Five Year Prospective Evaluation. 2014, University of Alabama at Birmingham, Graduate School.

30. Jakupovic, S., et al., Analysis of the abfraction lesions formation mechanism by the finite element method. Acta Inform Med, 2014. 22(4): p. 241-5.

31. Poiate, I.A.V.P., et al., Stress distribution in the cervical region of an upper central incisor in a 3D finite element model. Brazilian Oral Research, 2009. 23(2): p. 161-168.

32. Castelnuovo, J., et al., Fracture load and mode of failure of ceramic veneers with different preparations. J Prosthet Dent, 2000. 83(2): p. 171-80.

33. Prasanth, V., et al., Relation between Fracture Load and Tooth Preparation of Ceramic Veneers an in Vitro Study. Health Sciences, 2013. 2(3): p. 1-11. 